\title{
GMR
}

\section{Molecular cloning, characterization, and expression profiles of androgen receptors in spotted scat (Scatophagus argus)}

\author{
H.P. Chen*, S.P. Deng*, M.L. Dai, C.H. Zhu and G.L. Li \\ Key Laboratory of Aquaculture in South China Sea for Aquatic Economic, \\ Animal of Guangdong Higher Education Institutes, Fisheries College, \\ Guangdong Ocean University, Zhanjiang, China \\ *These authors contributed equally to this study. \\ Corresponding author: G.L. Li \\ E-mail: guangli211@163.com \\ Genet. Mol. Res. 15 (2): gmr.15027838 \\ Received October 10, 2015 \\ Accepted December 29, 2015 \\ Published April 7, 2016 \\ DOI http://dx.doi.org/10.4238/gmr.15027838
}

ABSTRACT. Androgen plays critical roles in vertebrate reproductive systems via androgen receptors (ARs). In the present study, the full-length spotted scat (Scatophagus argus) androgen receptor (sAR) cDNA sequence was cloned from testis. The sAR cDNA measured 2448 bp in length with an open-reading frame of $2289 \mathrm{bp}$, encoding 763 amino acids. Amino acid alignment analyses showed that the sARs exhibited highly evolutionary conserved functional domains. Phylogenetically, the sARs clustered within the $A R \beta$ common vertebrate group. Real-time polymerase chain reaction (RT-PCR) revealed that SAR expression varied in level and distribution throughout the tissues of both females and males. SAR expression was detected during testicular development by quantitative RT-PCR. The results showed that the highest transcription of SARs was observed in the mid-testicular stage, and remained at a high expression level until the latetesticular stage. In addition, the effects of 17a-methyltestosterone (MT) and estrogen $\left(E_{2}\right)$ on the expression of sARs in ovaries were determined using quantitative RT-PCR. SAR expression increased at 12 and $24 \mathrm{~h}$ post- 
MT treatment and decreased with $\mathrm{E}_{2}$ treatment. The present study provides preliminary evidence indicating gonadal plasticity of spotted scat under exogenous steroidal hormone treatments. It also provides a theoretical basis for sex reversal and production of artificial pseudo-males for female monosex breeding.

Key words: Sarcophagus argus; Androgen receptor; Steroid hormones; Testicular development

\section{INTRODUCTION}

Androgen is well known for its important roles in controlling reproduction by binding and activating androgen receptors (ARs). These receptors belong to the nuclear receptor superfamily (Apostolinas et al., 1999) and share a similar structure exhibiting three typical functional domains; the transactivation domain (TAD), the DNA binding domain (DBD), and the ligand binding domain (LBD). The TAD shows low-sequence identity, while the DBD is highly conserved among different species. The LBD contains conserved binding sites for ligands including testosterone $(T)$, 11-ketotestosterone (11-KT), methyldihydrotestosterone (MDHT), 17 $\alpha$-methyltestosterone (MT), and other pharmaceutical androgens (Brinkmann et al., 1999). As ligand-activated transcription factors, ARs mainly exert their genomic influences by binding to androgen-response elements to promote or repress the transcription of target genes.

To date, ARs have been identified and characterized in many fish species. In most fish, two AR subtypes (AR $\alpha$ and $A R \beta$ ) have been identified. These subtypes have been found in various species, including rainbow trout (Oncorhynchus mykiss) (Takeo and Yamashita, 1999), kelp bass (Paralabrax clathratus) (Sperry and Thomas, 1999), Japanese eel (Anguilla japonica) (Ikeuchi et al., 1999), Nile tilapia (Oreochromis niloticus) (Todo et al., 1999), Atlantic croaker (Micropogonias undulatus) (Sperry and Thomas, 2000), and the western mosquitofish (Gambusia affinis) (Ogino et al., 2004). However, this is not true for all teleosts. For example, there is only one AR subtype in goldfish (Pasmanik and Callard, 1988), fathead minnow (Pimephales promelas) (Wilson et al., 2004), sea bass (Dicentrarchus labrax) (Blázquez and Piferrer, 2005), zebrafish (Jørgensen et al., 2007), Spinibarbus denticulatus (Liu et al., 2009), and orange-spotted grouper (Epinephelus coioides) (Shi et al., 2010). This indicates a difference in genome duplication between fishes. During evolution, one of the duplicated AR genes might have been lost in a lineage-specific manner (Thornton, 2001).

Androgen is the key steroid hormone for both male and female reproduction (Yeh et al., 2003; Chakraborty et al., 2009). In S. denticulatus, AR expression was detected during testicular and ovarian recrudescence. AR mRNA expression in $S$. denticulatus was elevated during the earlyrecrudescing phase, and then decreased significantly at the late- and full-recrudescing stages (Liu et al., 2009). However, a weak transcript signal was also observed in the ovary, suggesting a potential AR function during early-recrudescing testicular development (Liu et al., 2009). In zebrafish, AR expression increased gradually, and reached a peak at late-testicular development stages (Jørgensen et al., 2007). A similar trend was observed in orange-spotted grouper (Shi et al., 2010). These reports suggest important AR roles in testicular development. ARs act as mediators in the androgen signal pathway and have been demonstrated to be affected by steroid hormones (e.g., androgen and estrogen). A number of studies have shown that exogenous androgens such as MT, MDHT, 11-KT, and T could promote AR expression in teleosts (He et al., 2003; Hossain et al., 2008; Shi et al., 2010; Gao et al., 2015), and play a role in the sex reversal process. However, 
estrogen $\left(E_{2}\right)$ potentially also increases AR expression in Atlantic croaker (Sperry and Thomas, 2000) and black porgy (He et al., 2003). Therefore, the physiological role of steroids in AR expression regulation is still unclear, and needs further investigation.

The spotted scat, Scatophagus argus, an euryhaline subtropical fish, is widely cultured in Indo-Pacific waters (Barry et al., 1993). The sexes differ markedly in growth rate: at 1 year of age, the growth rate of female fish is two times greater than that of males (Sivan and Radhakrishnan, 2011). For this reason, female monosex farming has been suggested to be beneficial in this species. However, there are few studies on the sex reversal of $S$. argus. At present, sex reversal induced by exogenous steroid hormones is considered as an effective method that has been widely used in many fishes (He et al., 2003; Shi et al., 2010; Rivero-Wendt et al., 2013a; Gao et al., 2015). As the key factor mediating the effect of androgens, ARs have been shown to be involved in female to male sex change. Therefore, it is necessary to obtain further information concerning the effects of exogenous steroids on ARs in spotted scat (sARs). In the present study, full-length sAR cDNA sequences were cloned, followed by sequence characterization and tissue distribution analyses. Furthermore, the expression profiles of gonadal SARs during testicular development and SAR transcription levels in ovaries treated with $\mathrm{MT}$ and $\mathrm{E}_{2}$ were determined.

\section{MATERIAL AND METHODS}

\section{Animal husbandry and tissue collection}

Spotted scat was obtained from Zhuhai Yucheng Fry Cultivation Base (Zhuhai, Guangdong, China). Fish were reared at temperatures of $24.5^{\circ}-29.2^{\circ} \mathrm{C}$ in indoor tanks. Fish were measured and sacrificed by decapitation following MS222 anesthetization. Their fresh tissues such as brain, pituitary, liver, gonad, kidney, heart, intestine, spleen, gill, and muscle were obtained and put in liquid nitrogen immediately after euthanasia and subsequently stored at $-80^{\circ} \mathrm{C}$. In order to confirm the gonadal stage, a piece of gonadal tissue from each fish was fixed in Bouin's fluid for histology. All animal experiments were conducted in accordance with the guidelines and approval of the Animal Research and Ethics Committees of Guangdong Ocean University.

\section{sAR cloning and sequence analysis}

Total RNA from adult $S$. argus (body weight ca. $250 \mathrm{~g}$ ) testes was prepared using Trizol reagent (Life Technologies, Carlsbad, CA, USA). The concentration of total RNA was measured using UV-spectrophotometry (Nanodrop 2000c, Thermo Scientific, Wilmington, DE, USA) and the quality was tested using $\mathrm{OD}_{260 / 280}(1.8-2.0)$ and $0.8 \%$ agarose gel with ethidium bromide (EB) (the $28 \mathrm{~S}$ and $18 \mathrm{~S}$ ribosomal RNA bands were clear and without smears). The first-strand CDNA was synthesized using the SMART-RACE cDNAAmplification Kit (Clontech, Takara, Shiga, Japan). Partial sARs were obtained using degenerate primer pairs and the full-length CDNA was cloned using the RACE-cloning methods following the SMART-RACE protocol. All primers used in this study are listed in Table 1 . The polymerase chain reaction (PCR) program was as follows: $2 \mathrm{~min}$ at $94^{\circ} \mathrm{C} ; 40$ cycles of $30 \mathrm{~s}$ at $94^{\circ} \mathrm{C}, 1$ min at $55^{\circ}-58^{\circ} \mathrm{C}, 1 \mathrm{~min}$ at $72^{\circ} \mathrm{C}$; and $10 \mathrm{~min}$ at $72^{\circ} \mathrm{C}$ for adenylation in the Bio-Rad thermocycler (BioRad Laboratories, Hercules, CA, USA). The PCR amplification products were examined on $1.5 \%$ EB-stained agarose gel. The potential bands were collected and purified using the E.Z.N.A. Gel Extraction Kit (Omega, Guangzhou, China) and subcloned into the pTZ57R/T-cloned vector (Thermo Scientific). Positive clones were sequenced by BGI Company (Shenzhen, China). 


Table 1. Sequences of PCR primers used.
\begin{tabular}{l|l|l|l}
\hline Gene & Purpose & Primer & $5^{\prime}$ to 3 ' sequence \\
\hline AR & Partail cDNA PCR & AR-F1 & GAGCACATGGATCCGGACAC \\
\cline { 2 - 4 } & & AR-R1 & TCCTYCTACTTRTGRAACAAGAT \\
\cline { 2 - 4 } & 5'-RACE PCR & AR-5R1 (first) & GCTYTGCASAGCTCYCTGGCTGT \\
\cline { 2 - 4 } & & AR-5R2 (nest) & GCTGTYTCTGAGATTGTGGCGCA \\
\cline { 2 - 4 } & 3'-RACE PCR & AF-3F1 (first) & GAACATCGGATGCACATATCCAC \\
\cline { 2 - 4 } & Quantitative RT-PCR and tissue distribution PCR & AF-3F2 (nest) & GATGAGACATCTTTCACAGGAG \\
\cline { 2 - 4 } & & Q-R & ATGAGCCAAACTAGCCGACAGC \\
\hline \multirow{3}{*}{-actin } & Quantitative RT-PCR and tissue distribution PCR & F & TCATGAAACAAAATGGGTTTA \\
\cline { 2 - 4 } & & R & CAGACAGCACAGTGTTGGCGT \\
\hline
\end{tabular}

Mixed bases: Y: C/T; R: A/G; M: A/C; S: G/C; H: A/C/T; K: G/T.

\section{SAR tissue distribution}

Total RNA was extracted from brain, pituitary, liver, gonad, kidney, heart, intestine, spleen, gill, and muscle of adult male and female $S$. argus (body weight ca. $250 \mathrm{~g}$ ). One microgram of total RNA from each tissue sample was treated with DNase I (Fermentas) and the first-strand cDNA was synthesized using the ReverTra Ace- $\alpha$ First-Strand cDNA Synthesis Kit (TOYOBO, Saitama, Japan). The sAR primers used for the tissue distribution and quantitative RT-PCR analyses are listed in Table 1 . Mock reactions without the reverse transcriptase as negative controls were done at the same time. The amplification regime consisted of 40 cycles of $15 \mathrm{~s}$ at $95^{\circ} \mathrm{C}, 55^{\circ} \mathrm{C}$ for $15 \mathrm{~s}$, and $72^{\circ} \mathrm{C}$ for $30 \mathrm{~s}$; followed by further amplification at $72^{\circ} \mathrm{C}$ for $5 \mathrm{~min}$. $\beta$-actin (Li et al., 2015) was used as an internal control. PCR products were separated on a $1.5 \%$ agarose gel and visualized with EB.

\section{Histological procedures}

Following $24 \mathrm{~h}$ in Bouin's fluid treatment, the gonadal tissue samples were transferred to $70 \%$ ethanol. Briefly, the fixed tissue samples were embedded in paraffin and were serially sectioned at $10 \mu \mathrm{m}$. The sections were stained with hematoxylin and eosin, and the classifications of testicular stage were determined under IQ50 light microscopy (Nikon, Tokyo, Japan). Five samples $(N=5)$ of each testicular stage were chosen to examine the sAR expressions.

\section{In vitro effect of exogenous steroid hormones on SAR expression}

The in vitro incubation of gonadal fragments was conducted following the methods of Zhang et al. (2007). Briefly, the ovaries from five adult female S. argus (body weight ca. $250 \mathrm{~g}$ ) were removed and washed three times with Hank's balanced salt solution. The ovaries were cut into small pieces, and placed onto a 24-well culture dish and pre-incubated with L15 medium (Life Technologies) for $2 \mathrm{~h}$ at $25^{\circ} \mathrm{C}$ in a humidified incubator under $5 \% \mathrm{CO}_{2}$. Subsequently, the preincubation medium was removed and a new medium containing either $\mathrm{E}_{2}$ or MT was added to treat the ovarian fragments and to reach a final concentration of $10^{-6} \mathrm{M}$. And the control groups were treated with the same medium without $\mathrm{E}_{2}$ and $\mathrm{MT}$ at the same time. After incubation for 6,12 and $24 \mathrm{~h}$, the ovarian fragments were collected and stored at $-80^{\circ} \mathrm{C}$. 


\section{Quantitative RT-PCR analysis for sAR expression}

The first-strand cDNA of each gonad was prepared following the manufacturer protocol of the ReverTra Ace- $\alpha$ First-Strand cDNA Synthesis Kit (TOYOBO). Quantitative RT-PCR was performed with the Roche LightCycler 480 (Roche, Bromma, Sweden) RT-PCR system using $S_{Y B R}(R)$ Premix Ex Taq ${ }^{T M}$ (Clontech Takara). Negative controls without templates were run simultaneously with the sARs. The quantitative RT-PCR conditions were as follows: denaturation at $94^{\circ} \mathrm{C}$ for $1 \mathrm{~min} ; 40$ cycles of $5 \mathrm{~s}$ at $94^{\circ} \mathrm{C}, 57^{\circ} \mathrm{C}$ for $10 \mathrm{~s}, 72^{\circ} \mathrm{C}$ for $20 \mathrm{~s}, 84^{\circ} \mathrm{C}$ for $10 \mathrm{~s}$ (fluorescent data collection); and termination with the melt curve analysis. The specificity of each primer pair and the quantitative RT-PCR data were evaluated using the melt curve of each gene. The threshold cycle values $(\mathrm{Ct})$ for SAR and $\beta$-actin were obtained using quantitative RT-PCR and data analysis using the $2^{\Delta C t}$ method.

\section{Statistical analysis}

Multiple-amino acid sequence alignments were performed using Clustal X (v. 1.81) (Thompson et al., 1994) and a protein phylogenetic tree was created using MEGA4.0 using the neighbor-joining method (Kumar et al., 2004). The data in the present study are reported as means \pm SE. Statistical differences were analyzed by one-way ANOVA of SPSS 13.0 (SPSS, Chicago, IL, USA). A significance level of $0.05(P<0.05)$ was used to denote statistical significance.

\section{RESULTS}

\section{sAR cloning and sequence analysis}

The different sAR cDNA were isolated from the spotted scat testes. The full-length sAR cDNA consisted of 2448 nucleotides with an open-read frame of $2289 \mathrm{bp}$, encoding 763 amino acid residues and exhibiting a similar sequence length as that found in other species (Figure 1). The spotted scat sARs belonged to the typical nuclear receptor family, containing the three typical functional domains TAD, DBD, and LBD (Figure 2). Multiple SAR alignments showed that the TAD domains of the SARs were the most variable regions with very low identity. The DBD domains possessed the DNA binding sites and the conserved P-box and D-box motifs. The LBD domain contained five conserved leucines, which constituted the zipper motif.

Phylogenetic analysis showed that the ARs could be divided into two evident teleost subclades. The SAR from $S$. argus clustered with the ARb subclade, similar to the ARs of sea bass and Atlantic croaker (Figure 3).

\section{SAR tissue distributions}

sAR expression was detected in the tissues of both male and female individuals (Figure 4). A strong expression signal was observed in both male and female pituitaries. Moderate sAR expression was found in the brain, ovary, gill, heart, muscle, and spleen in females, and in the testis in males. Low expression levels were detected in the liver and intestine in females. Similarly, low transcription signals were observed in the male brain, liver, heart, intestine, spleen, gill, and muscle. No expression signals were observed in male or female kidneys. 
1 TTC TGG GAA ATG AGC CAA ACT AGC CGA CAG CTA TCT TAT AAA AAA ATT TGG CCA GGG GTT

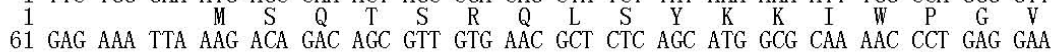
$21 \mathrm{E} \quad \mathrm{K} \quad \mathrm{L}$ K $\mathrm{T}$ D $S$ V V N A L S M A Q N P E E 121 AGT CGG ATC TGT TTC ACC AAA AAT TCA TCG GGA AAC AGT TCC GGC AGG CTG AAA GAG ACC

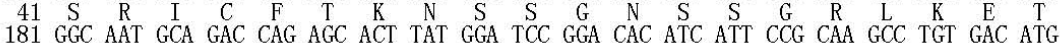
\begin{tabular}{lllllllllllllllllllll}
61 & $G$ & $N$ & $A$ & $D$ & $Q$ & $S$ & $T$ & $Y$ & $G$ & $S$ & $G$ & $H$ & $I$ & $I$ & $P$ & $Q$ & $A$ & $C$ & $D$ & $M$ \\
\hline
\end{tabular} 241 GAA AAA CAT TTC TGT CAA ACA GCT GCT CCT CAT GAG GAG TTG TTA AAC GCT GGC TGT CGT

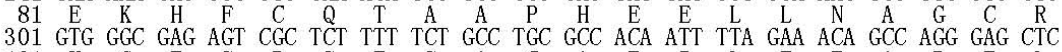

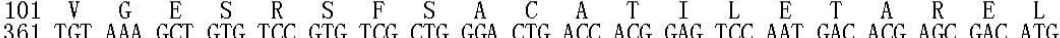

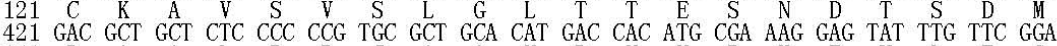

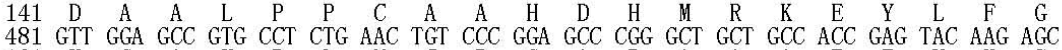

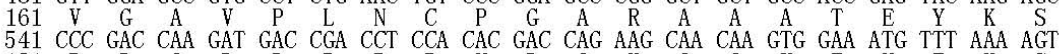

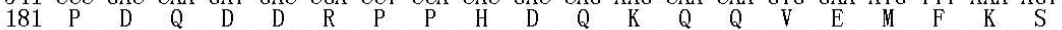
181 TCA GAG ACT GCT GCG CGT CTG CAG CAC TTC ACC TCC GCT CGG ACT TCT GTA GAT GAG CAA $201 \mathrm{~S}$ E T A A R L Q H F T S A R T S V D E Q

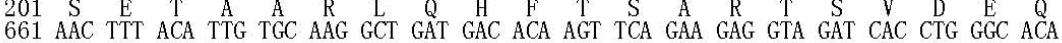

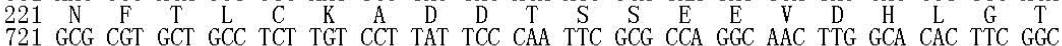

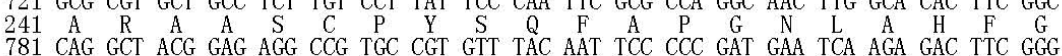

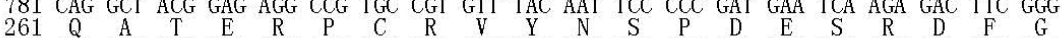

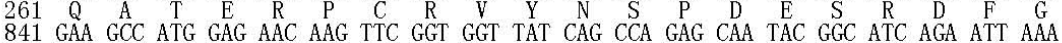

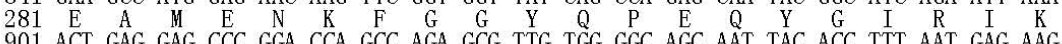
901 ACT GAG GAG CCC GGA CCA GCC AGA GCG TTG TGG GGC AGC AAT TAC ACC TTT AAT GAG AAG

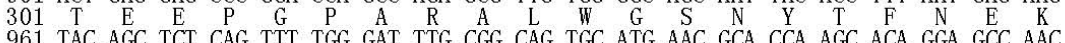
961 TAC AGC TCT CAG TTT TGG GAT TTG CGG CAG TGC ATG AAC GCA CCA AGC ACA GGA GCC AAC 1021 ACT GCA TTA TGT AAT CCA TAT GAG CGG AGC GTC GTG TGC CCC GAC CAG TGG TAC TCT GGC

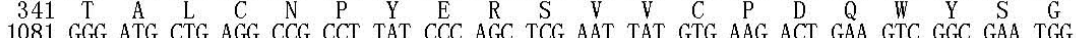

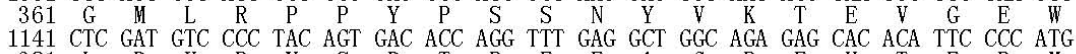

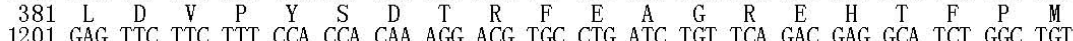
$401 \mathrm{E}$ F F F P P O R T C L I C S D E A S G C 1261 CAT TAC GGT GCT CTC ACC TGT GGC AGC TGC AAG GTT TTC TTC AAA AGA GCT GCA GAA GGC

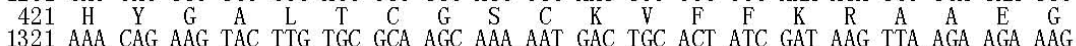

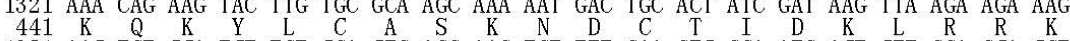

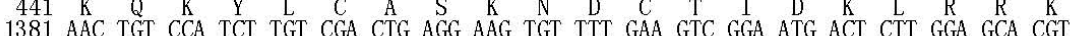

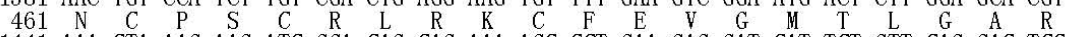
1441 AAA CTA AAG AAG ATC GGA CAG CAG AAA AGC CCT GAA GAG GAT CAT TCT GTT CAG GAC TCC

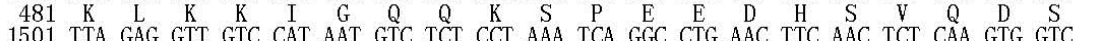

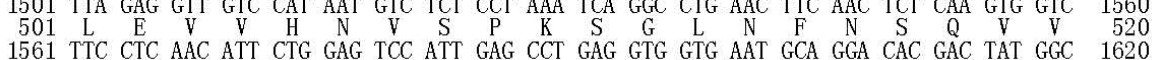
1561 TTC CTC AAC ATT CTG GAG TCC ATT GAG CCT GAG GTG GTG AAT GCA GGA CAC GAC TAT GGC 1620

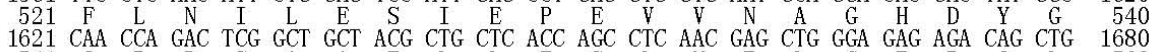
$541 \mathrm{Q} \quad \mathrm{P}$ D S A A T L L T S L N E L G E R Q L 1681 GTC AAA GTG GTC AAA TGG GCA AAA GGA TTG CCA GGT TTT AGA AAC CTC CAT GTG GAT GAT 1740

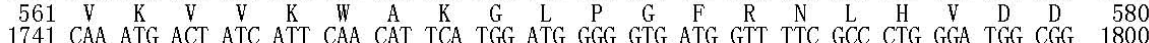
$\begin{array}{llllllllllllllllllllll}581 & Q & M & T & I & I & Q & H & S & W & M & G & V & M & V & F & A & L & G & W & R & 600\end{array}$ $\begin{array}{rlllllllllllllllllllll}601 & S & Y & K & N & V & N & S & R & M & L & Y & F & A & P & D & L & V & F & N & E & 620\end{array}$

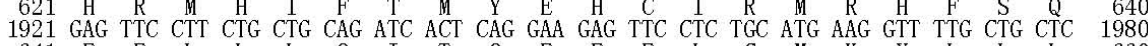

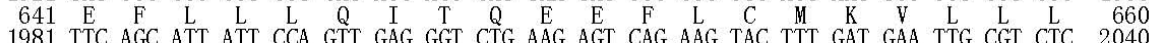

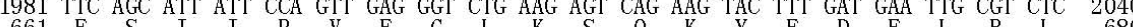

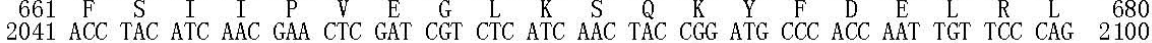
$681 \mathrm{~T}$ Y I N E L D R L I N Y R M P T N C S O 2101 AGA TTC TAC CAA CTC ACC CGA CTC CTG GAC TCT CTC CAG ATG ACA GTA AAG AAG CTC CAT 2160

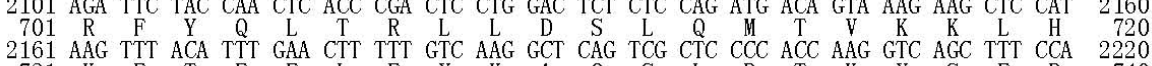

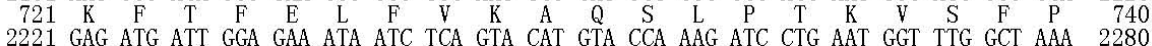
2221 GAG ATG ATT GGA GAA ATA ATC TCA GTA CAT GTA CCA AAG ATC CTG AAT GGT TTG GCT AAA 2280

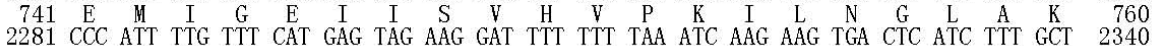

2281 CCC ATT TTG TTT CAT GAG TAG AAG GAT TTT TTT TAA ATC AAG AAG TGA CTC ATC TTT GCT 2340

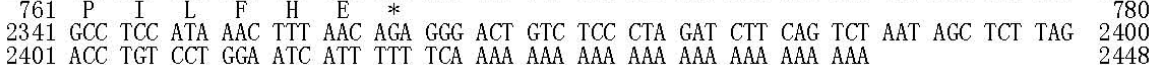
Figure 1. Nucleotide and deduced amino acid sequence of the sARs. The translation stop codon is designated with an asterisk. 


\begin{tabular}{|c|c|}
\hline & TAD domain \\
\hline SAR & $----M S Q T S R Q L S 9$ \\
\hline ZAR & MEVPVGLVEACESPDAVFHGPYOSVFQNVRVARASNPESLDISSSKKCGCLQEGSSREMR 60 \\
\hline & $\begin{array}{c}\text { MEVPVGLVEACESPDAVFHGPYQSVFQNVRVARASNPESLD ISSSKKCGCLQEGSSREMR } 60 \\
\text { :**: : }\end{array}$ \\
\hline SAR & YKKIWPGVEKLKT-DSVVNALSMAGNPEESRICFTKNSSGNSSGR---LKETGNADQS-T 64 \\
\hline dAR & CNKMWTVGAKIKT-GDAVSALSMAQNPEESPVYFTKNS SGNGADR---LKESDHADPN-T 64 \\
\hline ZAR & LSELSSFRRIICCPEKEYESASSVIQAAASRIHFLKSSSGSKSDSSLSSSGSGRTDATES 120 \\
\hline SAR & YGSGHIIPQACDNEKHFCQT-AAPHEELLN-AGCRVGESR-- - \\
\hline dAR & YGSGHTNSLACDMEKHCCQTAAAPQEELLN-ADCRVGDSR-------------SFSAC 108 \\
\hline $\mathrm{zAR}$ & 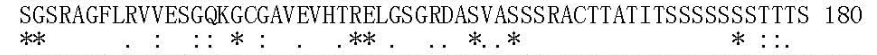 \\
\hline SAR & ATILETARELCKAVSVSLGLTTESNDTSDMD-AALPPCAAHDHMRKEYLFGVGAVPLNCP 166 \\
\hline $\mathrm{dAR}$ & ATISETARELCKAVSVSLGLAMESSDTSDVDGGTLHSCAANDHIRGEYLFGVGAVPLNRP 168 \\
\hline $\mathrm{ZAR}$ & 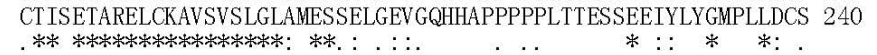 \\
\hline SAR & G----ARAAATEYKSPDQDDR-PPHDQKQQVEMFKSSETAARLQHFTSARTS------- 213 \\
\hline dAR & G----AQAAD--YKCPDRDDR-PLHGQKQLVEMFKTSETAARLHHLTSTWTS-------- 213 \\
\hline $\mathrm{ZAR}$ & 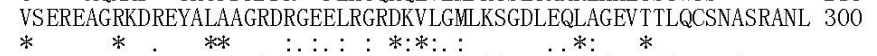 \\
\hline SAR & ---VDEQ-----NFTLCKADDTSSEEVDHLGT-ARAASCPYSQFAPGNLAHFGQA--TER 262 \\
\hline dAR & --VDEQ --- NFTMCKADDITSQK IDHLDTSTRAASCPYAQSAPGNLAHFGQARETEK 265 \\
\hline ZAR & 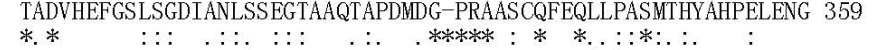 \\
\hline SAR & PCR-VYNSPDESRDFGEAMENKFGGYQPEQYGIRIKTEE-PGPARALWGSNYTFNEKYSS 320 \\
\hline dAR & PCR-VYKPPNEARDFAEAMENKFGGY-PEQYSVKIKSED-PESLAASWGTNYTFNEKYNS 322 \\
\hline zAR & 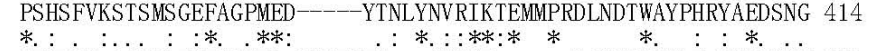 \\
\hline SAR & QFWDLR-QCMNAPSTGANTA-LCNPYER---SVVCP-----DQWYSGGMLR-PPYPSSN 368 \\
\hline $\mathrm{dAR}$ & QFWGS RQQCMNAHSTGASTAFICNPYER---SVVRP------EQWYPGGMLR-PPYPNSN 372 \\
\hline ZAR & HYGPPK--QRTPYATGHEPPFICNPYEYGRSTALVPRERPPHEQWYPGGYLTRHPYPNVP 472 \\
\hline & 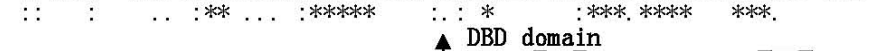 \\
\hline SAR & YVKTEVGEWLDVP-YSDTRFEAGREHTFPMEFF FPPQRTCLICSDEASGCHYGALTCGSC 427 \\
\hline dAR & YVKTEVGEWLDVA-YNDTRFEAGREHMFPMEFF FPPQRMCLICSDEASGCHYGALTCGSC 431 \\
\hline zAR & 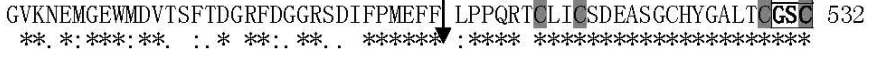 \\
\hline SAR & KVFFKRAAEGKQKYLCASKNDCT IDKLRRKNCPSCRLRKCFEVGMTLGARKLK KIGQQKS 487 \\
\hline $\mathrm{dAR}$ & $\overline{\overline{K V}}$ FFKRAAEGKQKYLC ASKND CT IDKLRRKNCPSCRLRKCFEAGMTLGARKLK $\mid \mathrm{KIGQQKN} 491$ \\
\hline $\mathrm{zAR}$ & 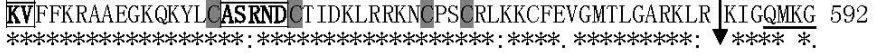 \\
\hline SAR & PEEDHSVQDSLEVVHNVSPKS GLNFNSQVVFLNILESIEPEWVNAGHDYGQPDSAATLLT 547 \\
\hline dAR & LEEDHPIQEPVEVIQNISPKSGLNFNSQLVFLNILESIEPEVVNAGHDYGQPDSADTLLT 551 \\
\hline $\mathrm{zAR}$ & 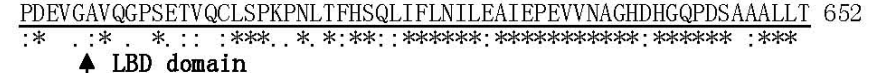 \\
\hline SAR & SLNEL] GERQLVKVVKWAKGLPGFRNLHVDDQMTIIQHSWMGVMVFALGWRSYKNVNSRML 607 \\
\hline $\mathrm{dAR}$ & SLNEL GERQLVKVVKWAKGLPGFRNLHMDDQMTVIQHSWMGVMVFALGWRSYKNANSRML 611 \\
\hline $\mathrm{ZAR}$ & 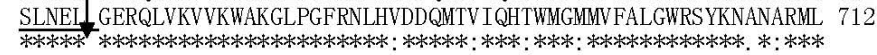 \\
\hline SAR & YFAPDLVFNEHRMHIFTMYEHCIRMRHFSQEFLLLQITQEEFLCMKVLLLFSIIPVEGLK 667 \\
\hline $\mathrm{dAR}$ & YFAPDLVFNEHRMHIS TMYEHCIRMKHLSQEFLLLQTTQEEFLCMKALLLFSILPVEGLK 671 \\
\hline ZAR & $\begin{array}{l}\text { YFAPDLVFNDRRMHVSSMYEHCVQMKHLSQEFVLLQVTQEEFLCMKALLLFSVIPVEGLK } 772 \\
* * * * * * * * *:: * * *:: * * * * *:: *: *: * * * *: * * *: * * * * * * * * * . * * * * *:: * * * * * *\end{array}$ \\
\hline SAR & SQKYFDELRLTYINELDRLINYRMPTNCSQRFYQLTRLLDSLQMTVKKLHKFTFELFVKA 727 \\
\hline dAR & SQKYFDELRLTYINELDRLINYRMTTNCSQRFYQLTRLLDSLQMTVKKLHQFTFDLFVQA 731 \\
\hline ZAR & 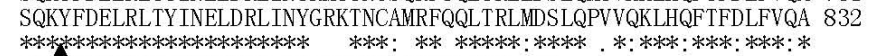 \\
\hline SAR & QSLPPTKVSFPEMIGEIISVHVPKILNGLAKPILFHE 763 \\
\hline dAR & QSL PTKVSFPEMIGEIISVHVPKILAGLAKPILFHE 767 \\
\hline $\mathrm{zAR}$ & $\begin{array}{l}\text { RSL PTKVSFPEMIAEIISVQVPKMLAGLSKPILFHK } 868 \\
: * * * * * * * * * * * * . * * * * *: * * *: * * * * * * * * * *:\end{array}$ \\
\hline
\end{tabular}

Figure 2. Amino acid alignment of the ARs. The amino acid sequences of the ARs are divided into different functional domains with vertical double arrows and the conserved amino acids are marked with asterisks. In the DNA bindingdomain ( $C$ domain), the eight conserved cysteine residues are highlighted in gray and the functional elements, including the P-box and D-box motifs, are boxed. The nuclear localization signal is underlined and the leucine zipper motif in the LBD domain is indicated by triangles. 


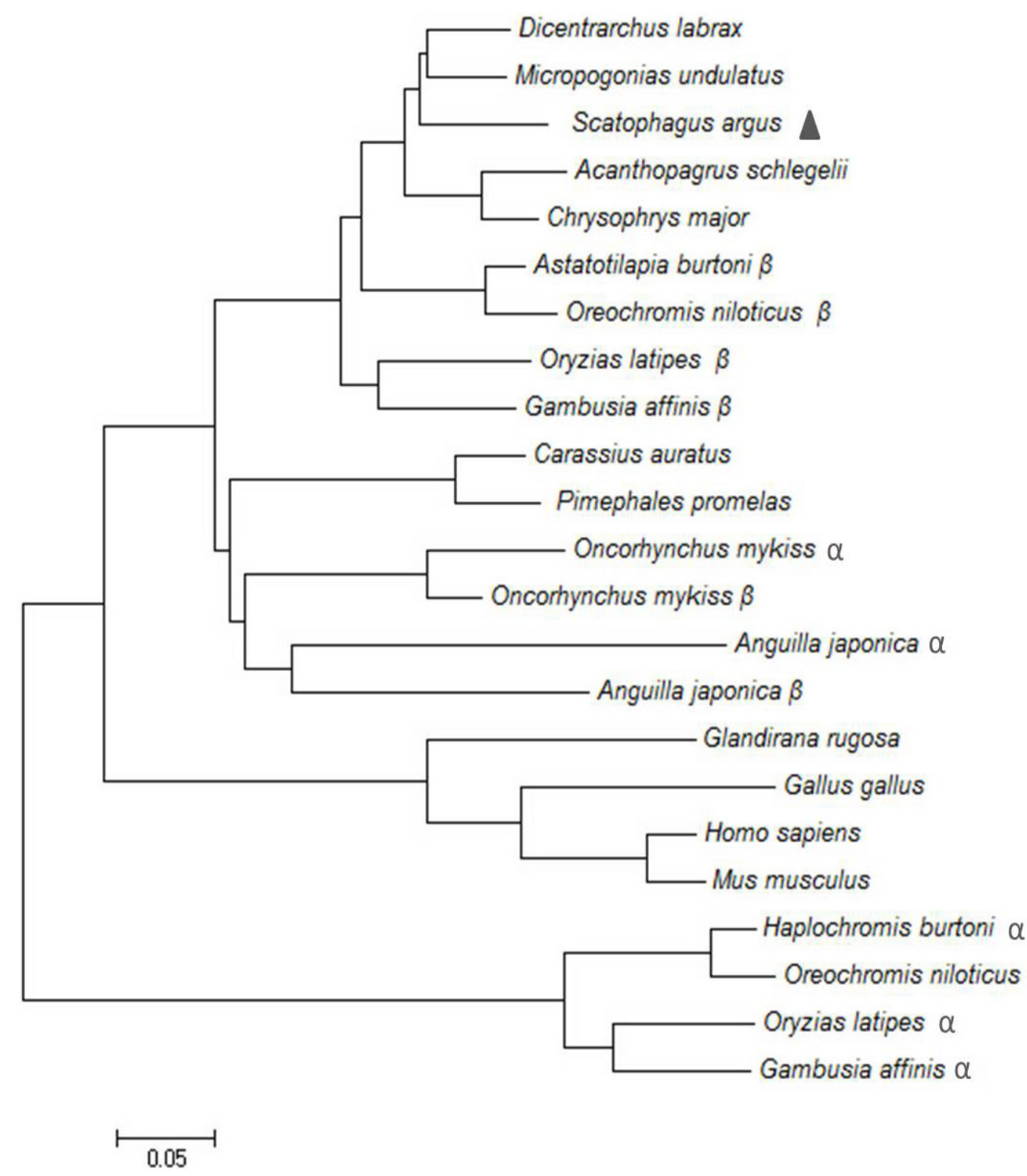

Figure 3. Phylogenetic analysis of AR in vertebrates. AR sequences used for analysis and their GenBank accession Nos. were Micropogonias undulatus (AAU09477.1); Oncorhynchus mykiss AR $($ NP_001117656.1); Haplochromis burtoni AR $\alpha$ (AAD25074.2); Oreochromis niloticus AR $\alpha$ (BAB20081.1); Oryzias latipesi AR $\alpha$ (BAI58983.1); Anguilla japonica AR $\alpha$ (BAA75464.1); Gambusia affinis AR $\alpha$ (BAD81045.1); Oncorhynchus mykiss AR (NP_001117657.1); Astatotilapia burtoni AR $\beta$ (AAL92878.2); Oreochromis niloticus AR $\beta$ (BAB20082.1); Oryzias latipes AR $\beta$ (NP_001098151.1); Anguilla japonica AR (BAA83805.1); Acanthopagrus schlegelii AR (AAO61694.1); Carassius auratus AR (AAM09278.1); Dicentrarchus labrax AR (AAT764 33.1); Pimephales promelas AR (AAF88138.2); Chrysophrys major AR (BAA33451.1); Gambusia affinis ARB (AAL92878.2); Gallus gallus ARa (NP_001035179.1); Glandirana rugosa AR (AB491724.1); Homo sapiens AR (AH002607.1); Mus musculus AR (CAA42160.1). The sAR is denoted by a triangle. The phylogenetic tree was constructed using MEGA4.0 by a neighbor-joining method. 


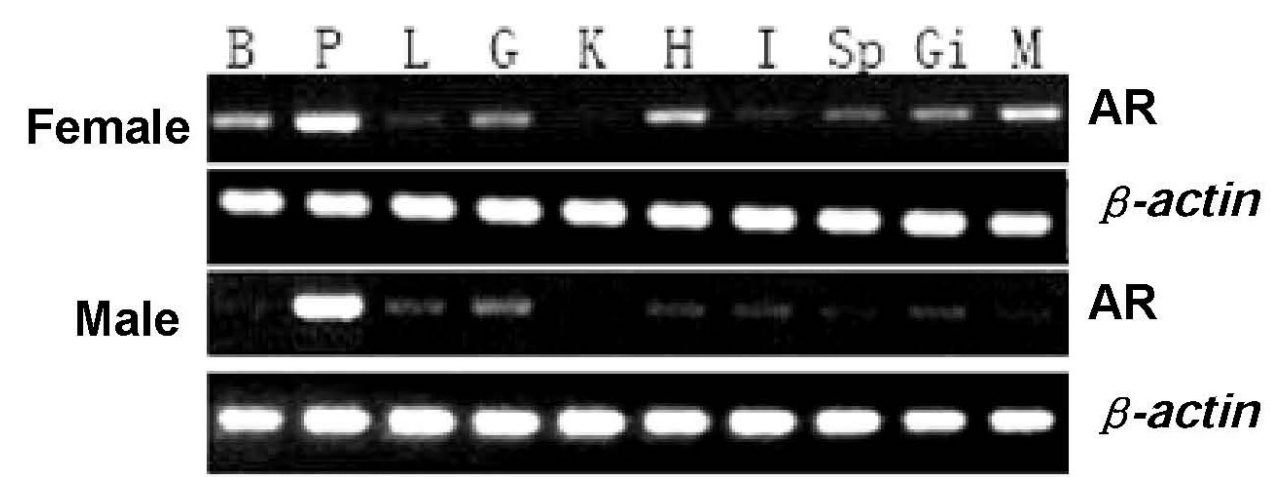

Figure 4. Tissue distributions of $s A R$ in various tissues by RT-PCR. The sAR mRNA expressions for females and males are shown in the top and bottom panels, respectively. $\beta$-actin was used as an internal control for the relative quantity of cDNA used in the PCRs. The tissues analyzed were: B, brain; P, pituitary; L, liver; G, gonad; K, kidney; H, heart; I, intestine; Sp, spleen; Gi, gill; M, muscle.

\section{sAR expression patterns during testicular development}

The gonadal morphology of testicular development in S. argus is shown in Figure 5. According to the testicular histology characteristics, the testicular development was divided into three stages. Testes with spermatogonia (SG) and spermatocytes (SC I) were considered to be in early-testicular stage (Figure 5A). The testes were assigned to the mid-testicular developmental stage once the spermatocytes (SC II) and spermatid (ST) appeared (Figure 5B). In the latedevelopmental stage, testes were filled with spermatozoa (SZ) (Figure 5C).

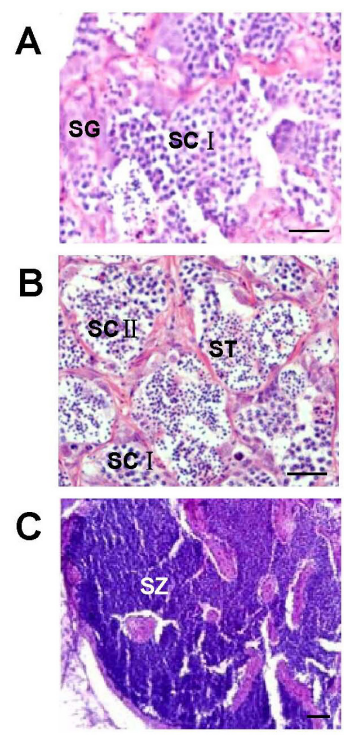

Figure 5. Gonadal histological sections of spotted scat during testicular development. A. Early-testicular stage with spermatogonia (SG) and spermatocytes (SC I); B. mid testicular stage with the spermatocytes (SC II) and spermatids (ST); C. late-testicular stage with the spermatozoa (SZ); Scale bar $=100 \mu \mathrm{m}$. 
Gonadal sAR expression was low in the early-testicular stage, reached peak transcription at the mid-testicular developmental stage, and decreased in the late-testicular developmental stage while remaining high compared to the early-testicular stage (Figure 6).

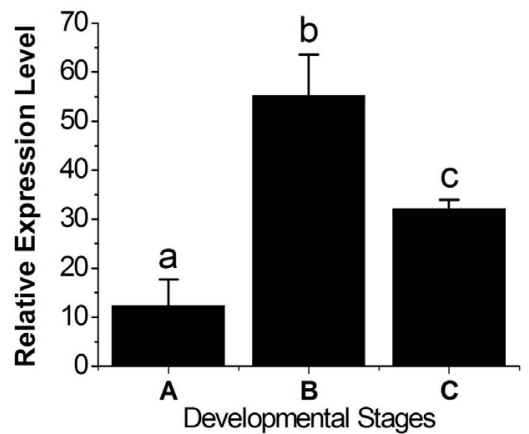

Figure 6. Expression profiles of sARs in the gonads of spotted scat during the early- (A), mid- (B), and late- (C) testicular stages. The data are reported as means $\pm S E(N=5)$ and values denoted with different lower case letters are significantly different at the probability level of $0.05(P<0.05)$.

\section{sAR expression patterns under exogenous steroid hormone treatments}

No significant differences between the control group and the MT and $E_{2}$ treatment groups were found in 6-h treatment. The SAR mRNA expression was significantly higher at 12 and $24 \mathrm{~h}$ in the MT treatment group than in the control group (Figure 7A). In the $E_{2}$ treatment group, the expression of sAR was significantly suppressed at 12 and $24 \mathrm{~h}$ time points (Figure 7B).
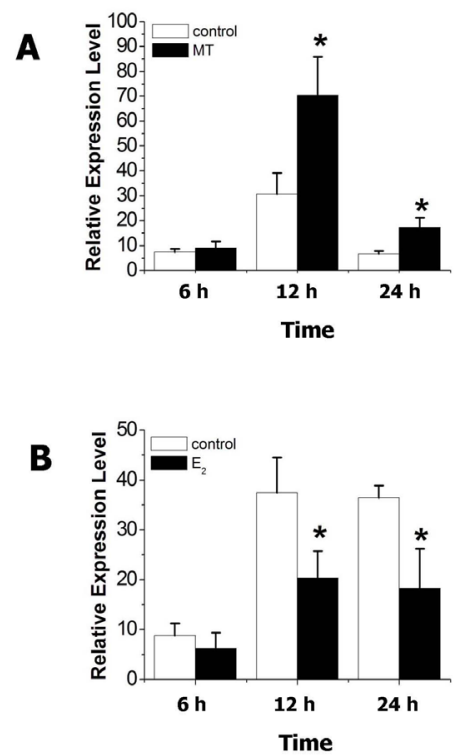

Figure 7. In vitro effect of $M T$ and $E_{2}$ on ovarian $S A R$ expression. The relative expression patterns of $S A R$ following MT (A) and $\mathrm{E}_{2}(\mathrm{~B})$ treatments, respectively. The data are reported as means $\pm \mathrm{SE}(\mathrm{N}=5$ for all treatments) and the values marked with an asterisk are significantly different from the control treatment at $\mathrm{P}<0.05$. 


\section{DISCUSSION}

In the present study, S. argus AR cDNA was characterized and sequence analysis revealed that the sequences shared the typical AR structures found in other species. Low domain similarities and variable lengths of the TAD domains in the ARs endowed their variable transactivation for specific physiological responses (Apostolinas et al., 1999). The ARs' DNA-binding domains exhibited the highest identities. They also contained conserved motifs and elements, such as the zinc-finger motifs, P-box, and D-box, which are essential to ensure precise reorganization (Shi et al., 2010). The sAR LBD had conserved leucine residues and shared high-sequence identity, which suggests ligand-specificity.

The RT-PCR analysis revealed that sARs were expressed in both male and female $S$. argus, and showed obvious tissue-specific expression patterns, implying multifunctionality of sARs in different tissues. This agrees with the results found in other teleosts (Huang et al., 2011). sAR expression was moderate in ovaries. Based on previous studies on fathead minnow (Wilson et al., 2004), Atlantic croaker (Sperry and Thomas, 2000), and kelp bass (Sperry and Thomas, 1999), AR signal blockage by antiandrogen would cause a significant decrease in aromatase expression in ovaries, and, thus, disrupt the normal endocrine function. Therefore, appropriate sAR expression in the ovaries might be associated with proper ovarian development (Rivero-Wendt et al., 2013b; Liu et al., 2014). Interestingly, sARs were observed to be most abundant in the pituitary of both males and females. This result differs from what has been found in other studies and may involve the positive and negative feedback regulations for the synthesis and release of gonadotropins (Breton and Sambroni, 1996; Huggard et al., 1996).

The androgen signal has been demonstrated to play a critical role during testicular development (Apostolinas et al., 1999; Chakraborty et al., 2009). In the present study, the sAR expression profile was determined during testicular development. A high mRNA level was observed in the mid-developmental stage, and remained high during the late-developmental stage. Similar results have been found in zebrafish (Jørgensen et al., 2007), orange-spotted grouper (Shi et al., 2010), and wrasse (Kim et al., 2002). In in S. denticulatus, serum T and 11-KT concentrations increased during the mid-testicular developmental stage (Liu et al., 2009; Huang et al., 2011), which is consistent with the SAR expression levels observed in the present study. This indicates that the androgen signal mediated by sARs mainly contributed during the mid-testicular developmental stage.

Gonadal development was triggered and maintained by the steroid hormones, especially $\mathrm{E}_{2}$ and MT (Yeh et al., 2003; Hossain et al., 2008). ARs have been shown to play critical roles during gonad development. ARs, as mediators in the gonads, would be affected by steroid hormones. According to previous studies, AR mRNA expression could be increased or suppressed by androgen treatment (Hillier et al., 1997; Larsson et al., 2002). Furthermore, $\mathrm{E}_{2}$ could also regulate AR transcription not only in vitro (Fujimoto et al., 1999; Yeh et al., 2003), but also in vivo (Miyamoto et al., 1998). Therefore, the role of $E_{2}$ and androgens in AR regulation remains unclear. In the present study, sAR expression increased in ovaries in vitro following MT treatment, which agrees with the results found in orange-spotted grouper (Shi et al., 2010) and in wrasse (Kim et al., 2002). SAR expression was significantly inhibited under $\mathrm{E}_{2}$ treatment, also in agreement with previous studies (Chang et al., 1997; He et al., 2003). Thus far, several studies have demonstrated that ARs likely constitute important factors associated with sex reversal that may be used in seeding and farming applications (Kim et al., 2002; Yeh et al., 2003; Hossain et al., 2008). As we know, androgens stimulate spermatogenesis and promote the development of testicular tissues via ARs. During female to male sex change, AR expression increases significantly in order to increase the 
androgen signal, thus contributing to stimulation of the atresia and apoptosis of ovarian tissues (Drummond, 2006; Katoh et al., 2006; Shi et al., 2010). In contrast, during male to female sex change, the AR mRNA levels must be decreased (He et al., 2003). Sex reversal is a complicated physiological process with ovarian degradation and testicular development, which is controlled by gonadal steroid hormones (Yeh et al., 2003). In the present study, sAR expression could be stimulated by MT and inhibited by $E_{2}$, suggesting gonadal plasticity produced by the exposure to exogenous steroid hormones in S. argus.

In conclusion, AR cDNA sequences from spotted scat were cloned and their tissue distributions were investigated. Furthermore, the expression levels, in relation to testicular development, were measured and the expression of ARs in ovaries in response to exogenous steroid hormone treatment was examined. The results suggest that sARs might play a dominant role in testicular development. Thus, we have preliminary evidence indicating gonadal plasticity of spotted scat under exogenous steroid hormone treatments. This may indicate a potential for sex reversal induction and female monosex farming.

\section{ACKNOWLEDGMENTS}

Research supported by the Guangdong Province Marine Fishery Science and Technology Promotion Project (\#A201408A06), the "Sail Project" of Guangdong Province, the Hainan International Science and Technology Cooperation project (\#KJHZ2015-08), and the Guangdong Ocean University Science Projects (\#E15181 and \#HDYQ2015002).

\section{REFERENCES}

Apostolinas S, Rajendren G, Dobrjansky A and Gibson MJ (1999). Androgen receptor immunoreactivity in specific neural regions in normal and hypogonadal male mice: effect of androgens. Brain Res. 817: 19-24. http://dx.doi.org/10.1016/ $\underline{\text { S0006-8993(98)01180-9 }}$

Barry TP, Castanos MT, Macahilig MPSC and Fast AW (1993). Gonadal maturation and spawning induction in female spotted scat (Scatophagus argus). J. Aqua. Trop. 8: 121-130.

Blázquez M and Piferrer F (2005). Sea bass (Dicentrarchus labrax) androgen receptor: cDNA cloning, tissue-specific expression, and mRNA levels during early development and sex differentiation. Mol. Cell. Endocrinol. 237: 37-48. http:// dx.doi.org/10.1016/j.mce.2005.04.001

Breton B and Sambroni E (1996). Steroid activation of the brain-pituitary complex gonadotropic function in the triploid rainbow trout Oncorhynchus mykiss. Gen. Comp. Endocrinol. 101: 155-164. http://dx.doi.org/10.1006/gcen.1996.0017

Brinkmann AO, Blok LJ, de Ruiter PE, Doesburg P, et al. (1999). Mechanisms of androgen receptor activation and function. J. Steroid Biochem. Mol. Biol. 69: 307-313. http://dx.doi.org/10.1016/S0960-0760(99)00049-7

Chakraborty A, Sreenivasulu K and Raman R (2009). Involvement of androgen receptor gene in male gonad differentiation in Indian garden lizard, Calotes versicolor. Mol. Cell. Endocrinol. 303: 100-106. http://dx.doi.org/10.1016/j.mce.2009.01.013

Chang CF, Lin BY, Lau EL, Lee MF, et al. (1997). The endocrine mechanism of sex reversal in the protandrous black porgy, Acanthopagrus schlegeli: a review. Chin. J. Physiol. 40: 197-205.

Drummond AE (2006). The role of steroids in follicular growth. Reprod. Biol. Endocrinol. 4: 16. http://dx.doi.org/10.1186/14777827-4-16

Fujimoto J, Hirose R, Sakaguchi H and Tamaya T (1999). Expression of size-polymorphic androgen receptor (AR) gene in ovarian endometriosis according to the number of cytosine, adenine, and guanine (CAG) repeats in AR alleles. Steroids 64: 526-529. http://dx.doi.org/10.1016/S0039-128X(99)00025-2

Gao J, Liu S, Zhang Y, Yang Y, et al. (2015). Effects of 17 a-methyltestosterone on transcriptome, gonadal histology and sex steroid hormones in rare minnow Gobiocypris rarus. Comp. Biochem. Physiol. Part D Genomics Proteomics 15: $20-27$. http://dx.doi.org/10.1016/j.cbd.2015.05.001

He CL, Du JL, Lee YH, Huang YS, et al. (2003). Differential messenger RNA transcription of androgen receptor and estrogen receptor in gonad in relation to the sex change in protandrous black porgy, Acanthopagrus schlegeli. Biol. Reprod. 69: 455-461. http://dx.doi.org/10.1095/biolreprod.102.015040 
Hillier SG, Tetsuka M and Fraser HM (1997). Location and developmental regulation of androgen receptor in primate ovary. Hum. Reprod. 12: 107-111. http://dx.doi.org/10.1093/humrep/12.1.107

Hossain MS, Larsson A, Scherbak N, Olsson PE, et al. (2008). Zebrafish androgen receptor: isolation, molecular, and biochemical characterization. Biol. Reprod. 78: 361-369. http://dx.doi.org/10.1095/biolreprod.107.062018

Huang BF, Sun YL, Wu FR, Liu ZH, et al. (2011). Isolation, sequence analysis, and characterization of androgen receptor in Southern catfish, Silurus meridionalis. Fish Physiol. Biochem. 37: 593-601.

Huggard D, Khakoo Z, Kassam G, Mahmoud SS, et al. (1996). Effect of testosterone on maturational gonadotropin subunit messenger ribonucleic acid levels in the goldfish pituitary. Biol. Reprod. 54: 1184-1191. http://dx.doi.org/10.1095/ biolreprod54.6.1184

Ikeuchi T, Todo T, Kobayashi T and Nagahama Y (1999). cDNA cloning of a novel androgen receptor subtype. J. Biol. Chem. 274: 25205-25209. http://dx.doi.org/10.1074/jbc.274.36.25205

Jøgensen A, Andersen O, Bjerregaard P and Rasmussen LJ (2007). Identification and characterization of an androgen receptor from zebrafish Danio rerio. Comp. Biochem. Physiol. A 146: 561-568.

Katoh H, Ogino $\mathrm{Y}$ and Yamada $\mathrm{G}$ (2006). Cloning and expression analysis of androgen receptor gene in chicken embryogenesis. FEBS Lett. 580: 1607-1615. http://dx.doi.org/10.1016/j.febslet.2006.01.093

Kim SJ, Ogasawara K, Park JG, Takemura A, et al. (2002). Sequence and expression of androgen receptor and estrogen receptor gene in the sex types of protogynous wrasse, Halichoeres trimaculatus. Gen. Comp. Endocrinol. 127: 165-173. http://dx.doi.org/10.1016/S0016-6480(02)00020-5

Kumar S, Tamura K and Nei M (2004). MEGA3: Integrated software for Molecular Evolutionary Genetics Analysis and sequence alignment. Brief. Bioinform. 5: 150-163. http://dx.doi.org/10.1093/bib/5.2.150

Larsson DG, Mayer I, Hyllner SJ and Förlin L (2002). Seasonal variations of vitelline envelope proteins, vitellogenin, and sex steroids in male and female eelpout (Zoarces viviparus). Gen. Comp. Endocrinol. 125: 184-196. http://dx.doi.org/10.1006/ gcen.2001.7740

Li GL, Zhang MZ, Deng SP, Chen HP, et al. (2015). Effects of temperature and fish oil supplementation on ovarian development and foxl2 mRNA expression in spotted scat Scatophagus argus. J. Fish Biol. 86: 248-260. http://dx.doi.org/10.1111/ ifb. 12578

Liu S, Wang L, Qin F, Zheng Y, et al. (2014). Gonadal development and transcript profiling of steroidogenic enzymes in response to 17a-methyltestosterone in the rare minnow Gobiocypris rarus. J. Steroid Biochem. Mol. Biol. 143: 223-232. http://dx.doi.org/10.1016/j.jsbmb.2014.03.001

Liu X, Su H, Zhu P, Zhang Y, et al. (2009). Molecular cloning, characterization and expression pattern of androgen receptor in Spinibarbus denticulatus. Gen. Comp. Endocrinol. 160: 93-101. http://dx.doi.org/10.1016/j.ygcen.2008.10.026

Miyamoto H, Yeh S, Lardy H, Messing E, et al. (1998). Delta5-androstenediol is a natural hormone with androgenic activity in human prostate cancer cells. Proc. Natl. Acad. Sci. USA 95: 11083-11088. http://dx.doi.org/10.1073/pnas.95.19.11083

Ogino Y, Katoh H and Yamada G (2004). Androgen dependent development of a modified anal fin, gonopodium, as a model to understand the mechanism of secondary sexual character expression in vertebrates. FEBS Lett. 575: 119-126. http:// dx.doi.org/10.1016/j.febslet.2004.08.046

Pasmanik M and Callard GV (1988). A high abundance androgen receptor in goldfish brain: characteristics and seasonal changes. Endocrinology 123: 1162-1171. http://dx.doi.org/10.1210/endo-123-2-1162

Rivero-Wendt CL, Miranda-Vilela AL, Ferreira MF, Amorim FS, et al. (2013a). Lack of genotoxicity in Astyanax bimaculatus and Oreochromis niloticus of 17 a-methyltestosterone used in fish hatcheries to produce male monosex populations. Genet. Mol. Res. 12: 5013-5022. http://dx.doi.org/10.4238/2013.October.24.14

Rivero-Wendt CL, Miranda-Vilela AL, Ferreira MF, Borges AM, et al. (2013b). Cytogenetic toxicity and gonadal effects of 17 a-methyltestosterone in Astyanax bimaculatus (Characidae) and Oreochromis niloticus (Cichlidae). Genet. Mol. Res. 12: 3862-3870. http://dx.doi.org/10.4238/2013.September.23.4

Shi Y, Zhang Y, Li S, Liu Q, et al. (2010). Molecular identification of the Kiss2/Kiss1ra system and its potential function during 17a-methyltestosterone-induced sex reversal in the orange-spotted grouper, Epinephelus coioides. Biol. Reprod. 83: 6374. http://dx.doi.org/10.1095/biolreprod.109.080044

Sivan G and Radhakrishnan C (2011). Food, feeding habits and biochemical composition of Scatophagus argus. Turkish J. Fish. Aquat. Sci. 11: 603-608.

Sperry TS and Thomas P (1999). Identification of two nuclear androgen receptors in kelp bass (Paralabrax clathratus) and their binding affinities for xenobiotics: comparison with Atlantic croaker (Micropogonias undulatus) androgen receptors. Biol. Reprod. 61: 1152-1161. http://dx.doi.org/10.1095/biolreprod61.4.1152

Sperry TS and Thomas P (2000). Androgen binding profiles of two distinct nuclear androgen receptors in Atlantic croaker (Micropogonias undulatus). J. Steroid Biochem. Mol. Biol. 73: 93-103. http://dx.doi.org/10.1016/S0960-0760(00)00069-8

Takeo J and Yamashita S (1999). Two distinct isoforms of cDNA encoding rainbow trout androgen receptors. J. Biol. Chem. 274: 5674-5680. http://dx.doi.org/10.1074/jbc.274.9.5674 
Thompson JD, Higgins DG and Gibson TJ (1994). CLUSTAL W: improving the sensitivity of progressive multiple sequence alignment through sequence weighting, position-specific gap penalties and weight matrix choice. Nucleic Acids Res. 22: 4673-4680. http://dx.doi.org/10.1093/nar/22.22.4673

Thornton JW (2001). Evolution of vertebrate steroid receptors from an ancestral estrogen receptor by ligand exploitation and serial genome expansions. Proc. Natl. Acad. Sci. USA 98: 5671-5676. http://dx.doi.org/10.1073/pnas.091553298

Todo T, Ikeuchi T, Kobayashi T and Nagahama Y (1999). Fish androgen receptor: cDNA cloning, steroid activation of transcription in transfected mammalian cells, and tissue mRNA levels. Biochem. Biophys. Res. Commun. 254: 378-383. http://dx.doi.org/10.1006/bbrc.1998.9919

Wilson VS, Cardon MC, Thornton J, Korte JJ, et al. (2004). Cloning and in vitro expression and characterization of the androgen receptor and isolation of estrogen receptor alpha from the fathead Minnow (Pimephales promelas). Environ. Sci. Technol. 38: 6314-6321. http://dx.doi.org/10.1021/es049771j

Yeh SL, Kuo CM, Ting YY and Chang CF (2003). Androgens stimulate sex change in protogynous grouper, Epinephelus coioides: spawning performance in sex-changed males. Comp. Biochem. Physiol. C Toxicol. Pharmacol. 135C: 375-382. http://dx.doi.org/10.1016/S1532-0456(03)00136-4

Zhang W, Zhang Y, Zhang L, Zhao H, et al. (2007). The mRNA expression of P450 aromatase, gonadotropin beta-subunits and FTZ-F1 in the orange-spotted grouper (Epinephelus Coioides) during 17alpha-methyltestosterone-induced precocious sex change. Mol. Reprod. Dev. 74: 665-673. http://dx.doi.org/10.1002/mrd.20642 